\title{
EM DEFESA DA APRENDIZAGEM DE INGLÊS NA ESCOLA PÚBLICA: CONSIDERAÇÕES SOBRE CRENÇAS DE ALUNOS ADOLESCENTES
}

\section{IN DEFENSE OF ENGLISH LANGUAGE LEARNING IN PUBLIC SCHOOLS: CONSIDERATIONS ON ADOLESCENT LANGUAGE LEARNERS' BELIEFS}

Fernando Silvério de Lima *

Resumo: Neste artigo, analisamos algumas crenças de alunos adolescentes sobre a aprendizagem do inglês na Escola Pública, tendo por base pesquisa realizada com alunos de uma turma de $1^{\circ}$ Ano do Ensino Médio, de uma escola pública localizada em cidade do noroeste paranaense. Como instrumentos, contamos primeiramente com um questionário semiaberto, complementado com notas e observações em campo. Os resultados analisados qualitativamente mostram que os alunos acreditam na possibilidade de aprender língua inglesa no próprio contexto, mesmo em face de eventuais limitações contextuais. A Escola Pública é vista pela maioria dos alunos como melhor contexto para aprender, seguido pelos cursos particulares e viagens ao exterior. Outro fator observado é a relação intrínseca entre as crenças dos aprendizes e seu contexto, uma vez que enfatizam repetidamente o apreço pelo próprio ambiente de aprendizagem e rejeitam crenças de outrem que menosprezam a qualidade da Escola Pública e elevam a do ensino privado.

Palavras-chave: Crenças. Escola Pública. Língua inglesa.

Aвsтract: This paper analyzes some adolescent students' beliefs about learning English in public schools. The study used an open-ended questionnaire, which was complemented with field notes and classroom observations. The results were qualitatively analyzed and indicate that students believe in the possibility of learning English in their own context, despite the contextual constraints. Public schools are perceived by most students as the best place to learn, followed by private language courses and traveling abroad. Another aspect observed was the intrinsic relationship between students' beliefs and their context, as they repeatedly emphasize their

\footnotetext{
"Doutorando em Estudos Linguísticos pela UNESP de São José do Rio Preto - UNESP/IBILCE. Mestre em Letras pela Universidade Federal de Viçosa - UFV. E-mail: limafsl@hotmail.com.
} 
respect for their own learning environment and reject beliefs that try to undervalue the quality of public schools and overvalue private schools.

KEYwords: Beliefs. Public schools. English language.

\section{INTRODUÇ̃̃o}

Vários podem ser os motivos para sustentar a crença de que não é possível aprender uma língua estrangeira (LE) no ensino público, como o excesso de turmas por professor, excesso de alunos por sala, indisciplina, graduação como única fonte de formação profissional, dentre outros fatores. Diante destes exemplos, uma pergunta inicial que nos inquieta é a de saber o que os alunos pensam a respeito da aprendizagem de uma língua estrangeira na Escola Pública e quais crenças possuem sobre a aprendizagem de línguas com base em suas experiências de vida escolar. Desde a década de 1980, no exterior, e mais especificamente na década de 1990, no Brasil, alguns pesquisadores têm se dedicado ao estudo das crenças e como estas podem direcionar as ações dos aprendizes em relação ao desempenho e engajamento para a aprendizagem.

Neste trabalho, observamos uma turma de adolescentes de uma escola pública de uma cidade de porte médio localizada no noroeste do Paraná, levantando crenças sobre aprendizagem neste ambiente. Este interesse surgiu a partir do primeiro contato com o grupo no período de observação de campo, em que foi possível perceber atitudes negativas (falta de interesse e de envol- vimento nas atividades, indiferença, etc.) na aula de língua inglesa. Nossas observações nos revelaram a necessidade de investigar os fatores contextuais que têm afetado o desenvolvimento das aulas.

\section{Pressupostos teóricos \\ CRENÇAS NO ENSINO DE LÍNGUAS}

A pesquisa de crenças no ensino de línguas cresceu consideravelmente desde os trabalhos mais conhecidos da década de 1980 (HORWITZ, 1987; WENDEN, 1987). Na década de 1990, aparecem os primeiros trabalhos sobre crenças em solo brasileiro. E ao fim dessa e nos anos posteriores, a proporção de pesquisas em LA sobre crenças cresce consideravelmente na chamada abordagem contextual de investigação (BARCELOS, 2001).

Nesta referida abordagem, as pesquisas consideram as crenças como um construto social, situado em um ambiente que pode influenciar as crenças dos alunos e dos professores. Além disso, dentre os diversos contextos de ensino e aprendizagem, novas pesquisas têm buscado investigar as crenças dos sujeitos da Escola Pública (ANDRADE, 2004; BASSO, 2006; COELHO, 2005; LIMA, 2012; LUVIZARI, 2007; LYONS, 2009; PITELI, 2006; STURM, 2007; ZOLNIER, 2007, só para citar alguns). Essas pesquisas 
têm considerado tanto professores quanto alunos, investigando as crenças que são construídas nesses contextos.

Neste trabalho, o foco de investigação são os adolescentes de uma turma de Ensino Médio de Escola Pública. Enfatizamos o sujeito adolescente por dois motivos: (I) a lacuna de pesquisas em LA que considerem o adolescente como foco principal da pesquisa, sendo que os professores são os que mais convivem com alunos adolescentes diariamente; e (II) considerando que este é período de transição marcado por mudanças afetivas, biológicas e cognitivas (MACOWSKI, 1993), ele pode estar relacionado às experiências vivenciadas e nas crenças construídas (LIMA, 2012; PAJARES, 2006).

O conceito de crenças que nos orienta é o de Barcelos (2006), a partir da definição que preconiza crenças enquanto:

Uma forma de pensamento, como construções da realidade, maneiras de ver e perceber o mundo e seus fenômenos, co-construídas em nossas experiências e resultantes de um processo interativo de interpretação e (re)significação. Como tal, crenças são sociais (mas também individuais, dinâmicas, contextuais e paradoxais). (op. cit, p. 18, grifo nosso).

Portanto, para compreender o conceito na Linguística Aplicada é importante considerarmos as percepções dos envolvidos no processo de aprendizagem de uma nova língua e as experiências pessoais, sejam elas individuais e/ou coletivas em contextos de aprendizagem. Assim, trazemos ainda uma perspectiva sociocultural para compreensão de crenças (ALANEN, 2003). Pois além de considerá-las enquanto um construto social e individual, que abarca as experiências e subjetividades das pessoas, nós compreendemos que, no contexto da sala de aula, elas têm potencial de mediação, atuando como ferramentas que medeiam as atividades de aprender e ensinar línguas. Elas podem auxiliar em nossas escolhas e ações, funcionando como uma lente (RICHARDS, 1998), um parâmetro ou uma bússola (LIMA, 2012).

Nas obras originais de Vygotsky (1962), o psicólogo soviético ressaltava o papel do contexto social na transformação dos seres humanos (COLE; WERTSCH, 1996), e o caráter social do desenvolvimento nas investigações com crianças em sociedades escolarizadas. Em seus estudos, o conceito de mediação sugere que a relação entre o ser humano e o mundo não se dá de maneira direta, mas indiretamente, por um elo que une os dois elementos, estabelecendo assim a mediação.

No conceito de mediação, a mente humana e o mundo que nos cerca são mediados por ferramentas, como o uso de signos. Tendo em mente a concepção marxista de trabalho como fator de transformação das sociedades, e que é utilizando ferramentas que o homem age no mundo, a noção de mediação foi fundamental para os estudos de Vygotsky sobre o pensamento e linguagem. Essa terminologia passa a se fazer presente nos trabalhos de crenças, tendo em vista compreender de que maneiras as crenças 
podem ser utilizadas como ferramentas na atividade de aprender línguas. Elas podem explicar, por exemplo, desde as decisões dos aprendizes, os parâmetros que orientam suas escolhas, até mesmo as ações dos alunos em contextos específicos. Alanen (2003) sugere ainda que elas podem emergir em atividades interativas, quando os aprendizes são levados a refletir conscientemente sobre seu papel e as condições disponíveis para sua aprendizagem.

O CONTEXTO SOCIOCULTURAL DA Escola PÚBLICA

O ensino do inglês na Escola Pública, assim como o da língua materna, está previsto na Lei de Diretrizes e Bases da Educação Nacional (BRASIL, 1996) como direito dos estudantes, e a partir de outros documentos nacionais, como os Parâmetros Curriculares Nacionais (doravante PCNs) e diretrizes estaduais, alguns objetivos são estabelecidos para o cumprimento deste direito. Como mostram os PCNs, há a preocupação em "restaurar o papel da Língua Estrangeira na formação educacional" (BRASIL, 1998, p.19), visto que o desprestígio da língua inglesa perpassa não apenas os discursos da falha da educação pública no contexto brasileiro (ALGEBAILE, 2009), mas também está presente nas vozes de pais e alunos (DIAS; COX-PETERSON, 2006; LIMA, 2012).

$O$ ensino da língua inglesa no contexto da Escola Pública é entendido por professores e pesquisadores como um processo complexo. Sua complexidade está ligada principalmente aos inúmeros problemas e limitações que são encontrados em diferentes estados brasileiros. No campo da pesquisa de crenças, por exemplo, este tipo de contexto tem sido um dos mais populares entre as dissertações e teses defendidas em programas de pós-graduação no país. A quantidade de pesquisas desde a década de 1990 é grande; e a partir de 2000 , quando os estudos atentaram principalmente para a relação do contexto com as crenças dos sujeitos ali inseridos, a expansão foi extremamente significativa, evidenciada em inúmeros trabalhos (ANDRADE, 2004; COELHO, 2005; BASSO, 2006, PITELI, 2006; STURM, 2007; ZOLNIER, 2007; LYONS, 2009; LIMA, 2012; apenas para ilustrar com alguns mais recentes).

No quesito 'crenças sobre aprender inglês na Escola Pública', os estudos têm mostrado que os alunos acreditam na possibilidade de aprender inglês, mas veem essa possibilidade ser comprometida por uma série de fatores que são enumerados em pesquisas como as de Andrade (2004), Coelho (2005), Basso (2006), Piteli (2006), Zolnier (2007), dentre outras. Alguns dos fatores mais recorrentes são: a carga horária semanal insuficiente, o desinteresse e a indisciplina das turmas, o desprestígio da língua inglesa. Esses mesmos fatores, por sua vez, fazem com que os professores desses alunos acreditem que o ensino nesses contextos ocorre aquém do esperado, sendo possível oferecer apenas uma base dos conteúdos programados.

Ainda na relação 'crença e contexto', podemos notar a presença da identidade dos 
aprendizes nos ambientes socioculturais de aprendizagem. Ao mencionar estudos da aprendizagem situada, Barcelos (2000) sugere que a aprendizagem, além de identidades, é um processo que constrói crenças. A noção de identidade pode estar ligada aos mais diferentes fatores, como a aceitação (de si ou de um grupo), o julgamento e a constituição daquilo que concebemos como o que é ser um aprendiz de línguas. Qual seria, portanto a relação entre o contexto e a identidade de alunos e professores? De maneira sucinta, os contextos onde atuamos e interagimos com outras pessoas passam a fazer parte de nossa trajetória de desenvolvimento. Como mostrado nos estudos socioculturais de Vygotsky (1962), todas as formas de interação e desenvolvimento humano ocorrem em contextos caracterizados por traços culturais que definem sociedades e que nos foram passadas e serão transmitidas às futuras gerações (OLIVEIRA, 1997 para uma discussão acerca do desenvolvimento infantil em sociedades escolarizadas).

Assim, os contextos socioculturais fazem parte daquilo que somos, e independentemente de suas limitações, podem ser entendidos, ou não, como ambientes ideais, ou que nos oferecem um conforto necessário. Tendo em vista essas reflexões, buscamos compreender como uma turma de adolescentes retrata suas crenças sobre aprender inglês numa escola pública. Como apresentaremos nas seções seguintes, estas questões aqui discutidas tornam-se extremamente recorrentes.

\section{Procedimentos Metodológicos}

Nosso estudo se caracteriza como pesquisa qualitativa de base etnográfica (ANGROSINO, 2009; SILVERMAN, 2009). Tal tipo de pesquisa nos revela ser uma importante fonte para investigação e, de acordo com Moita Lopes (1996, p. 22), ela considera "o foco na percepção que os participantes têm da interação linguística e do contexto social em que estão envolvidos [...]". Esta preocupação em relação aos sujeitos da pesquisa (e suas percepções) retoma principalmente a necessidade de constante reflexão acerca dos métodos e instrumentos selecionados em nossos estudos qualitativos (FLICK, 2009a), tendo em vista o papel das pesquisas desta natureza na sociedade contemporânea (FLICK, 2009a, 2009b; GIBBS, 2009; SILVERMAN, 2009) e mais especificamente no escopo da Linguística Aplicada.

A turma observada é composta por 27 alunos, com faixa etária entre 15 e 18 anos. Os alunos estão matriculados no $1^{\circ}$ Ano do Ensino Médio, no período matutino, e a escola está localizada num bairro periférico de uma cidade do interior do Paraná. Os dados a serem apresentados fazem parte de um corpus mais amplo formado a partir do uso de diferentes instrumentos qualitativos: questionários, entrevistas, notas de campo e gravações de aula em vídeo. Por questões de espaço e escopo, tomamos como base principal o primeiro instrumento citado 1 .

A investigação sobre as crenças do grupo em relação ao processo de

\footnotetext{
${ }^{1}$ Uma versão do questionário está disponível em anexo,
} ao final deste texto. 
ensino-aprendizagem (a partir de questionários) foi realizada durante o período de observação de aulas. Como fonte de coleta de dados primária, elaboramos um questionário misto, com alternativas e questões abertas (SILVERMAN, 2009), na fase inicial que pretendia investigar as crenças destes alunos no processo de ensino-aprendizagem de LE na escola pública. No dia de aplicação, 23 alunos estavam presentes e responderam o questionário. Quanto a este tipo de instrumento, Vieira Abrahão (2006, p.222) justifica que o tipo misto "tem sido empregado com o propósito de levantar informações pessoais, curriculares, expectativas e mesmo crenças, para comprovar ou não dados coletados por métodos qualitativos", sendo desta maneira bastante relevante para nosso propósito de conhecer sobre as crenças dos alunos da turma.

ANálise dos DADos

CRENÇAS DOS ALUNOS ADOLESCENTES SOBRE APRENDIZAGEM DE INGLÊS

A respeito do contexto ideal para aprender inglês a maioria dos alunos acredita na Escola Pública (48\%) como o contexto ideal. A respeito deste fato, percebemos como o aluno adolescente busca afirmar e marcar seu território pelo argumento que figura em grande parte das justificativas a respeito de a Escola Pública $(E P)^{2}$ ser o contexto ideal.

${ }^{2}$ Por questões de estilo utilizaremos ao longo do texto ora Escola Pública e ora EP.
Gráfico I - O contexto ideal para aprender inglês

\section{Crenças sobre o contexto ideal para aprender língua inglesa}

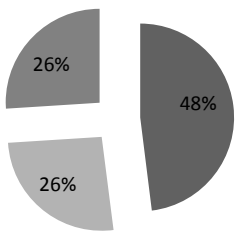

\author{
- ESCOLA PÚBLICA \\ ESCOLA DE IDIOMAS \\ - MORANDO NO \\ EXTERIOR
}

Como mostra a figura 1, a Escola Pública é, de acordo com as crenças dos alunos, o melhor lugar para aprender inglês. Em segundo lugar, vemos um empate entre o curso de idiomas e as viagens ao exterior como alternativas mais recomendadas.

Esta crença na possibilidade de aprender inglês na Escola Pública corrobora os resultados de Coelho (2005), Andrade (2004), e difere de Lima (2012). Nos dois primeiros trabalhos, os alunos revelaram, em diferentes instrumentos, que as condições para aprendizagem em seu contexto podem não ser as desejáveis por professores e alunos, mas não descartam a possibilidade de aprender. Contrariamente, seus professores, em ambos os estudos, mostram crenças diferentes, geralmente influenciadas por fatores contextuais (tempo, material, comportamento da turma, dentre outros), justificando que essas condições não possibilitam uma aprendizagem mais aprofundada, mas apenas porções de um conteúdo mais básico (COELHO, 2005).

Já em Lima (2012), os adolescentes da Escola Pública reconhecem alguns fatores 
contextuais como limitadores de sua aprendizagem, que também justificam a (des) crença observada no grupo estudado. No entanto, após um período interventivo, alguns sinais de mudança na (des)crença foram notados, sugerindo que o processo de mudança de crenças pode ser alcançado.

Os estudantes da presente pesquisa caracterizaram sua escola sob quatro aspectos, que apresentamos na figura abaixo:

Figura 1- Caracterização da Escola Pública como contexto ideal

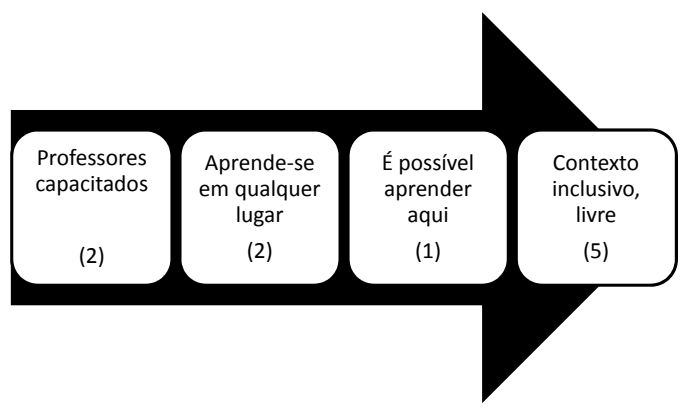

Dentre o grupo de dez alunos (10) que veem a Escola Pública como contexto ideal, cinco (5) deles ressaltam seu contexto como um ambiente inclusivo, diferentes dos demais, onde podem aprender e se expressar com liberdade. Os excertos que apresentamos abaixo constituem exemplos das respostas dos alunos.

A1: "Porque fala sobre e para o público, com todas as pessoas, e todos os que estão na sala de aula".

A2: "É melhor porque aqui todos dão opiniões, podem falar à vontade".

A3: "Porque todos que estão presentes dão opiniões sinceras"
A4: "Porque é mais fácil de aprender aqui, e também porque a gente aprende com pessoas que a gente já conhece, e o ensino da matéria é muito bom."

A5: "Porque aqui todo mundo tem o direito de aprender, ninguém fica de fora".

Os excertos mostram a sala de aula de uma escola pública como um contexto bem quisto pelos alunos, onde suas vozes são ouvidas. No dia da aplicação do questionário, alguns alunos comentaram que imaginavam em outros contextos a falta de liberdade que tinham na sua escola. E em face de ambientes repreensivos ou mais desconfortáveis aos estudantes, pelo menos no plano subjetivo de suas crenças, toma-se a realidade deles como a mais segura.

Esta crença que permeia e medeia as ações dos alunos (ALANEN, 2003; LIMA, 2012; NEGUERUELA-AZAROLA, 2011) nos auxilia na compreensão da sua relação com a identidade dos aprendizes. Como as crenças se baseiam em experiências e interpretações das mesmas, elas reconstroem as trajetórias dos aprendizes para aprender inglês, e consequentemente mostram ser parte daquilo que somos e das decisões que tomamos.

Nos demais cinco (5) alunos dessa categoria, outras três caracterizações da EP ressaltam a aprendizagem como algo concebível (1), a capacidade dos professores deles (2), visto como aptos para ensinar, além da visão equiparada de que tanto no contexto público como particular, aprender é algo possível (2). No tocante ao contexto

\footnotetext{
${ }^{3}$ Informação registrada em nossas notas de campo
} 
particular, mais especificamente o dos cursos de idiomas, seis alunos apontam três possíveis caracterizações que explicam porque acreditam ser esse o melhor local, conforme pode ser visualizado na figura a seguir.

Figura 2 - Caracterização do curso de idiomas como contexto ideal

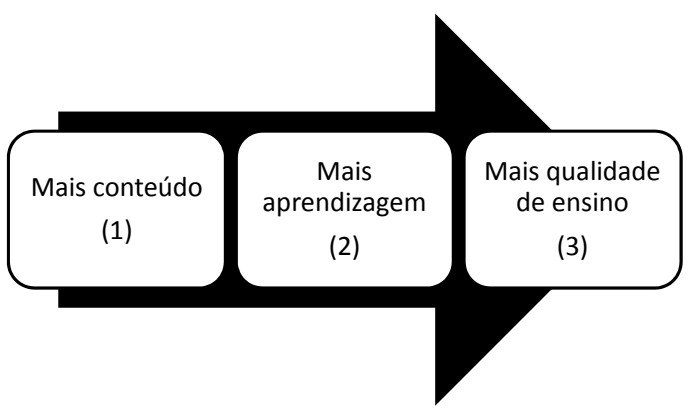

A característica mais recorrente foi apontada por três alunos (3) e diz respeito à qualidade de ensino. Eles acreditam que nos cursos privados a aprendizagem é melhor, mesmo que nenhum deles tenha frequentado algum desses cursos anteriormente ${ }^{4}$. As outras três características atribuídas pelos alunos consideram ainda a crença de que nos cursos particulares os alunos têm acesso a mais conteúdos (1) e, portanto maior aprendizagem (2).

A6: "Porque nos cursinhos particulares sempre tem mais aprendizagem dos alunos".

A7: "Porque o ensino é mais puxado e tem mais matéria"
A8: "Porque com nos cursos particulares dá pra aprender mais coisas sobre a língua inglesa, já na escola é muitas pessoas querendo saber ao mesmo tempo".

A9: "Porque tem algumas qualidades melhores de ensino"

A1o: "O ensino é melhor e o aluno aprende mais"

A11: "Porque o ensino particular é o melhor"

Tais resultados retomam os estudos de Barcelos (2011) e Lima e Candido-Ribeiro (mimeo), acerca da idealização dos cursos particulares como o contexto dos sonhos (LIMA; CANDIDO-RIBEIRO, mimeo) ou o eldorado da aprendizagem (BARCELOS, 2011). $\mathrm{Na}$ análise de uma narrativa, Barcelos (2011) verifica a relativização entre ser aluno de EP e de cursinho, em que um aluno com experiência nos dois contextos demonstra maior valorização do último, como local responsável por sua aprendizagem ${ }^{5}$. E em um estudo com adolescentes de escola regular privada, Lima e Candido-Ribeiro (mimeo) identificam na crença dos alunos que os cursos livres superam o contexto regular como a preferência para aprender inglês.

Empatado com os cursos idiomas (seis alunos em cada), temos as viagens ao exterior. Todas as justificativas ecoam a crença de que no exterior a necessidade de comunicação (para fins reais) obrigará o aluno a aprender a língua, como evidenciado em alguns dos excertos que selecionamos:

\footnotetext{
${ }^{5} \mathrm{O}$ sujeito em questão era um graduando de Letras em Curso de Especialização (latu sensu).
}

${ }^{4}$ Dados coletados no questionário, junto com outras informações pessoais para identificação de perfis individuais. 
A12: "Porque você convive com as pessoas falando a inglês todos os dias, ai você aprende bastante".

A13: "Porque você aprende mais rápido praticando".

A14: "Porque ele é obrigado a aprender".

A15: "Porque você tem que falar e também entender o que os outros falam".

A16: "Porque pra sobreviver você vai ter que falar inglês".

Aparentemente, notamos o fator relevância nas crenças dos alunos (A12-A16), pois quanto maior for a exposição à língua e necessidade de uso autêntico, maiores serão as chances de a pessoa conseguir aprender. Outra crença atrelada aqui pode ser a compreensão de uma relação direta entre um estímulo que gera uma resposta. Assim, os alunos podem crer que o simples fato de viajar resultará no desenvolvimento linguístico do aprendiz, como se esta premissa fosse verdadeira em todos os casos.

Contudo, mesmo em face de três contextos de aprendizagem, ressaltamos como a crença do grupo se volta para a Escola Pública como o ideal. Quando questionados novamente sobre sua escola e a possibilidade de aprender inglês ali, vários deles saem em sua defesa, enfatizando que ali há sim condições para aprender.

A17: "Bom eu acho que na escola pública é igual às outras, se prestarem é atenção fácil. E não tem dessa de que a particular é melhor, é tudo a mesma coisa".
A18: "Na escola pública é igual às outras, não há diferenças".

A19: "Bom eu acho que a escola pública é igual às outras, não tem dessa de que a particular é melhor. O inglês é uma língua que às vezes fica muito fácil de aprender ou não, depende do seu professor e do seu desempenho.".

A20: "Eu diria pra que ele viesse, porque o ensino é o mesmo".

A21: "Sim, porque a escola pública tambémé boa".

A22: "Na escola publica o ensino é tão bom quanto o da particular".

Gostaríamos de ressaltar que em momento algum o questionário induziu alguma relação entre os diferentes contextos ou tentou sugerir ao grupo que existia um contexto mais adequado que o outro. Somente em uma questão ${ }^{6}$, em que os alunos deveriam selecionar o contexto ideal é que as opções foram apresentadas. Cogitamos essas opiniões como tentativas de afirmação para nós pesquisadores, os corpos estranhos que se aproximam dos contextos e tentam compreender as diferentes crenças e interpretações da realidade. Em conversas posteriores com o grupo, alguns alunos comentaram, por exemplo, não gostar da visão desprestigiada com que algumas pessoas veem a Escola Pública e a supervalorização do Ensino Privado7.

\footnotetext{
${ }^{6}$ Trata-se da questão cinco do questionário apresentado em anexo.

${ }^{7}$ Além de conversas informais, esses dados foram registrados em um grupo focal realizado ao final da pesquisa e gravado em vídeo.
} 
Novamente, percebemos a relação crença e identidade, uma vez que a visão do contexto como ruim ou fraco também afeta aqueles que estão ali inseridos. A escola e a sala de aula já fazem parte da vida daqueles alunos, pois dentre outras características, ali é o único contexto formal de aprendizagem de uma nova língua a que eles têm acesso, e onde acreditam na possibilidade de desenvolver suas potencialidades (VYGOTSKY, 1962). Portanto, conceber que eles não estudam no melhor contexto implica que não poderão ter as mesmas oportunidades, ou que eles não serão os melhores aprendizes. Mesmo que suas ações não correspondam totalmente à crença destacada - sendo indisciplinados ou desinteressados com a disciplina, por exemplo - a visão inferiorizada da EP faz com que os alunos se expressem de forma a valorizar um contexto que faz parte deles.

\section{Considerações Finais}

Ao longo deste artigo, tecemos algumas considerações sobre as crenças de alunos adolescentes sobre a aprender inglês na Escola Pública, tomando como base as respostas de 23 alunos em um questionário semiaberto. Percebemos que a maioria do grupo aponta o contexto de Escola Pública como o ideal para aprender, seguido pelos cursos particulares e viagens ao exterior. Mesmo que nenhum desses alunos tenha frequentado cursos extras ou viajado ao exterior, observamos entre esses adolescentes a valorização do seu contexto de aprendizagem: a Escola Pública, sendo que ela é entendida como contexto inclusivo, onde os alunos têm a voz e a vez para se expressar.
Com base nestes resultados podemos ponderar sobre algumas questões que inspiram estudos futuros. Primeiramente, a questão da (des)crença no contexto de Escola Pública parece ser um aspecto que merece mais estudos em Linguística Aplicada. Apesar dos resultados deste estudo corroborarem trabalhos anteriores (ANDRADE, 2004; COELHO, 2005), estudos mais recentes identificaram uma (des)crença em turmas de inglês, que se mostra como desafio contemporâneo aos professores (LIMA, 2012).

A respeito da relação identidade, crença e contexto, concluímos que tais fatores, observados sob uma perspectiva sociocultural, possibilitam compreender a construção inerente daquilo que somos, de onde viemos e consequentemente no que acreditamos, como base em todos esses aspectos que constituem a jornada de aprender uma nova língua. A defesa da Escola Pública, percebida nas crenças destes alunos, nos revela que por mais que as práticas pedagógicas sejam afetadas por limitações contextuais, ou que existam pessoas que buscam enxergar apenas as limitações da educação pública (ALGEBAILE, 2009), existem aprendizes que reconhecem em seu contexto a possibilidade e a potencialidade para aprender. Assim, acreditar já é um primeiro passo dado, já vislumbrando o próximo: as ações desses alunos para aprender inglês na Escola Pública.

\section{REFERÊNCIAS}

ALANEN, R. A sociocultural approach to young learners' beliefs about language learning. In: KALAJA, P.; BARCELOS, A.M.F. (Eds.). Beliefs about SLA: new research approaches. 
Dordrecht: Kluwer Academic Press, 2003. p.55-85.

ALGEBAILE, E. Escola pública e pobreza no Brasil: a ampliação para menos. Rio de Janeiro: Lamparina, FAPERJ, 2009.

ANDRADE, A. A. C. Crenças de alunos e professores da escola pública sobre a aprendizagem de língua na escola regular. 2004. Dissertação (Mestrado em Estudos da Linguagem). Universidade Federal do Rio Grande do Norte, Natal, 2004.

ANGROSINO, M. Etnografia e observação participante. Tradução de José Fonseca. Porto Alegre: Artmed, 2009.

BARCELOS, A. M. F. Understanding teachers' and stu-dents' language learning beliefs in experience: a deweyan approach. Tese de doutorado. The University of Alabama, Tuscaloosa, AL, USA, 2000.

- Metodologia de pesquisa das crenças sobre aprendizagem de línguas: Estado da arte. Revista Brasileira de Linguística Aplicada, v. 1, n. 1, p. 71-92, 2001.

- Cognição de professores e alunos: tendências recentes na pesquisa de crenças sobre ensino e aprendizagem de línguas. In. BARCELOS, A. M. F.; VIEIRA-ABRAHÃO, M. H. (Orgs.). Crenças e ensino de línguas: foco no professor, no aluno e na formação de professores. Campinas: Pontes, 2006. p.15-41

. Lugares (im)possíveis de se aprender inglês no Brasil: crenças sobre aprendizagem de inglês em uma narrativa. In: LIMA, D. C. (Org.). Inglês em escolas públicas não funciona? uma questão, múltiplos olhares. São Paulo: Parábola, 2011. p.147-158

BASSO, E. A. Quando a crença faz a diferença. In. BARCELOS, A. M. F.; VIEIRA-ABRAHÃO, M. H. (Orgs.). Crenças e ensino de línguas: foco no professor, no aluno e na formação de professores. Campinas: Pontes, 2006. p.15-41 BRASIL. Ministério da Educação. Parâmetros Curriculares Nacionais. MEC/SEE, 1998.

BRASIL. Lei $n^{\circ}$ 9.394. Lei de Diretrizes e Bases da Educação Nacional. Brasília, 1996.

COELHO, H. H. É possível aprender inglês na escola? crenças de professores e alunos sobre o ensino de inglês em escolas públicas. Dissertação (Mestrado em Estudos Linguísticos). Universidade Federal de Minas Gerais, Belo Horizonte, 2005.

COLE, M.; WERTSCH, J. Beyond the individual-social antimony in discussions of Piaget and Vygotsky. Human Development. v.34: p.250-256, 1996.

DIAS, M. H. M; ASSIS-PETERSON, A. A. $O$ inglês na escola pública: vozes de pais e alunos. Polifonia, v. 2, n. 12, p.107-128, 2006.

FLICK, U. Desenho da pesquisa qualitativa. Tradução de Roberto Cataldo da Costa. Porto Alegre: Artmed, 2009a.

Qualidade na pesquisa qualitativa. Tradução de Roberto Cataldo da Costa. Porto Alegre: Artmed, 2009b.

GIBBS, G. Análise de dados qualitativos. Tradução de Roberto Cataldo da Costa. Porto Alegre: Artmed, 2009.

HORWITZ, E. K. Surveying students' beliefs about lan-guage learning. In: WENDEN, A.; RUBIN, J. (Orgs.). Learner strategies in language learning. London: Prentice Hall International, 1987. p.110-129.

LIMA, F. S. Signs of change in adolescents' beliefs about learning english in public school: a sociocultural perspective. 2012. 245f. Dissertação (Mestrado em Letras) Universidade Federal de Viçosa, Minas Gerais, 2012. 
.; CANDIDO-RIBEIRO, D. Crenças de alunos de uma escola privada sobre a aprendizagem do inglês. mimeo.

LYONS, M. O Ensino de língua inglesa numa escola pública de Mato Grosso: a relação crença - contexto. 2009. Dissertação (Mestrado em Estudos da Linguagem) Universidade Federal do Mato Grosso, 2009.

MACOWSKI, E. A. B. A construção do ensino/aprendizagem de língua estrangeira com adolescentes. 1993. 262f. Dissertação (Mestrado em Linguística Aplicada) Universidade Estadual de Campinas, Campinas, 1993.

MOITA LOPES, L. P. Oficina de linguística aplicada. Campinas: Mercado de Letras, 1996. NEGUERUELA-AZAROLA, E. Beliefs as conceptualizing activity: a dialectical approach for the second language classroom. System, v.39, n.3, p.359-369, 2011.

OLIVEIRA, M. K. Vygotsky: aprendizado e desenvolvimento-um processo sóciohistórico. São Paulo: Scipione, 1997.

PAJARES, F. Self-efficacy during childhood and adolescence: implications for teacher and parents. In: ; URDAN, T. (Eds.). Self-

efficacy beliefs of adolescents. Greenwich, CT: Information Age Publishing, 2006.

PITELI, M. L. A leitura em língua estrangeira em um contexto de escola pública: relação entre crenças e estratégias de aprendizagem. Dissertação. (Mestrado em Estudos Lingüísticos). UNESP, São José do Rio Preto, 2006.

RICHARDS, J. C. Teacher beliefs and decision making. In: (Ed.). Beyond training. Cambridge: Cambridge University Press, 1998. p. 65-85.

SILVERMAN, D. Interpretação de dados qualitativos: métodos para análise de entrevistas, textos e interações. 3.ed. Trad. Magda Lopes. Porto Alegre: Artmed, 2009.

STURM, L. As crenças de professores de inglês de escola pública e os efeitos na sua prática: um estudo de caso. 2007. Tese (Doutorado em Letras) - Universidade Federal do Rio Grande do Sul, Porto Alegre, 2007.

VIEIRA-ABRAHÃO, M. H. Metodologia na investigação de crenças. In: VIEIRA ABRAHÃO, M. H; BARCELOS, A. M. (Orgs.). Crenças e ensino de línguas: foco no professor, no aluno e formação de professores. Campinas: Editores, 2006. p.219-231.

VYGOTSKY, L. Thought and language. Cambridge, MA: MIT Press, 1962.

WENDEN, A. How to be a successful language learner: insights and prescriptions from L2 learners. In: WENDEN, A.; RUBIN, J. Learner strategies in language learning. New Jersey: Prentice Hall Regents, 1987.

ZOLNIER, M. C. A. P. Língua inglesa: expectativas e crenças de alunos e de uma professora do ensino fundamental. 2007. 140f. Dissertação (Mestrado em Linguística Aplicada)-Universidade Estadual de Campinas, Campinas, 2007. 
ANEXO

QUESTIONÁRIO SOBRE CRENÇAS

Língua Inglesa em CONTEXTo de Ensino Público

Prezado aluno,

Este questionário tem por objetivo fazer um levantamento sobre algumas crenças sobre aprendizagem de inglês na escola pública. Tanto o nome da escola quanto dos alunos não serão revelados, portanto, sinta-se livre para expressar suas opiniões.

\section{1- Você gosta de língua inglesa?}

$\bigcirc \operatorname{sim}$

Não Nunca pensei sobre o assunto

2- Você gosta da disciplina de língua inglesa?

Sim

Não

Nunca pensei sobre o assunto

3- O que você mais gosta nas aulas de língua inglesa?

4- O que você menos gosta nas aulas de língua inglesa?

5- Selecione qual contexto você considera ideal para aprender melhor

Escola Pública $\bigcirc$ cursos de Idiomas $\bigcirc$ Viagens ao exterior

6- Justifique sua escolha anterior

7- Como você se sente na aula de inglês?

\begin{tabular}{l|l|l} 
Confiante & $\bigcirc$ Indiferente & Feliz \\
Tímido & $\bigcirc$ Outro & $\bigcirc$ Motivado \\
Entediado & $\bigcirc$ Ansioso & $\bigcirc$ Ridículo \\
Perdido & $\bigcirc$ Intimidado & $\bigcirc$ Estressado \\
\hline Á vontade & &
\end{tabular}

8- Para você, qual a finalidade de aprender língua inglesa?

\begin{tabular}{l|l|l}
$\bigcirc$ Viajar & $\bigcirc \begin{array}{l}\text { Adquirir mais } \\
\text { conhecimento }\end{array}$ & $\bigcirc$ Vestibular \\
\hline Lazer & $\bigcirc$ Está na grade escolar & $\bigcirc$ Usar a internet \\
\hline Outra & $\bigcirc \begin{array}{l}\text { Obter melhores } \\
\text { empregos }\end{array}$ & \\
\hline
\end{tabular}




\section{9- Comente a questão anterior}

\section{0- Questão hipotética}

Imagine que um amigo seu que não conhece sua escola está pensando em se transferir para lá, ele(a) gosta muito de estudar língua inglesa, e gostaria de saber de você, sinceramente, se é possível aprender bem língua inglesa na escola pública (falar, ler, escrever, ouvir), o que você diria para ele(a)? (Justifique sua resposta)

Recebido para publicação em 15 jun. 2012.

Aceito para publicação em 22 nov. 2012. 